\title{
Behavioral emergency in the elderly: a descriptive study of patients referred to an Aggression Response Team in an acute hospital
}

This article was published in the following Dove Press journal:

Clinical Interventions in Aging

31 October 2016

Number of times this article has been viewed

\author{
Daniel Simpkins' \\ Carmelle Peisah ${ }^{2,3}$ \\ Irene Boyatzis' \\ 'Division of Rehabilitation and Aged \\ Care, Hornsby Ku-ring-gai Hospital, \\ ${ }^{2}$ School of Psychiatry, University \\ of New South Wales, ${ }^{3}$ Discipline \\ of Psychiatry, University of Sydney, \\ Sydney, NSW, Australia
}

Aim: The management of severely agitated elderly patients is not easy, and limited guidelines are available to assist practitioners. At a Sydney hospital, an Aggression Response Team (ART) comprising clinical and security staff can be alerted when a staff member has safety concerns. Our aims were to describe the patient population referred for ART calls, reasons for and interventions during ART calls, and complications following them.

Methods: Patients 65 years and older referred for ART calls in the emergency department or wards during 2014 were identified using the Incident Information Management System database and medical records were reviewed. Demographic and clinical data were collected.

Results: Of 43 elderly patients with ART calls, 30 had repeat ART calls. Thirty-one patients (72\%) had underlying dementia, and $22(51 \%)$ were agitated at the time of admission. The main reasons for ART calls were wandering and physical aggression. Pharmacological sedation was used in $88 \%$ of the ART calls, with a range of psychotropics, doses, and routes of administration, including intravenous (19\%) and, most commonly, midazolam (53\%). Complications were documented in $14 \%$ of cases where sedation was used.

Conclusion: We observed a high frequency of pharmacological sedation among the severely agitated elderly, with significant variance in the choice and dose of sedation and a high rate of complications arising from sedation, which may be an underestimate given the lack of postsedation monitoring. We recommend the development of guidelines on the management of behavioral emergency in the elderly patients, including de-escalation strategies and standardized psychotropic guidelines.

Keywords: aged, aggression, delirium, dementia, antipsychotic agents, benzodiazepines

\section{Introduction}

The management of severely agitated elderly patients in the acute hospital setting is not easy. ${ }^{1-4}$ Urgent safety issues for both patient and staff coexist with diagnostic priorities in a setting not geared to first-line nonpharmacological strategies of meeting psychosocial and emotional needs of patients. ${ }^{5}$ The adverse outcomes of cognitively impaired older people in hospital are well documented and include prolonged length of stay, increased mortality, polypharmacy, and psychotropic use. ${ }^{6-8}$

However, agitation among elderly patients in the hospital setting is common, and needs to be managed given its association with some of these adverse outcomes. ${ }^{9}$ The most common causes of agitation in the elderly are delirium or behavioral and psychological symptoms of dementia (BPSD), and less commonly, a primary psychosis. ${ }^{1,2}$ Delirium affects an estimated $14 \%-56 \%$ of all hospitalized elderly patients, ${ }^{10}$ while an estimated $60 \%$ of people with dementia will experience symptoms
Correspondence: Daniel Simpkins Hornsby Ku-ring-gai Hospital, Palmerston Road, Hornsby, Sydney, NSW 2077, Australia Tel $+6|4| 2712555$ Fax +6I 294779162 Email simpkinsdaniel@gmail.com

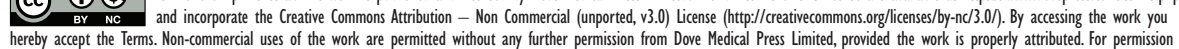
for commercial use of this work, please see paragraphs 4.2 and 5 of our Terms (https://www.dovepress.com/terms.php). 
of agitation or aggression at some stage during the course of their disease. ${ }^{11}$

There is broad consensus that the first-line management of both delirium and BPSD involves thorough assessment and treatment of the underlying cause of the delirium or trigger for the BPSD in conjunction with nonpharmacological strategies. ${ }^{10,12}$ Acute hospital settings, particularly emergency departments (EDs), are not geared to this, but rather to pharmacological strategies, ideally used as a last resort due to high risk-to-benefit ratios in the elderly. However, despite the existence of various guidelines on the management of both delirium and dementia, including within Australia, ${ }^{13-15}$ they often lack detailed advice on the pharmacological and nonpharmacological management of patients with severe agitation. ${ }^{16}$ This is probably a reflection of the lack of highquality randomized control trials in this domain. ${ }^{17-21}$ While there are guidelines for the management of the agitated patients, ${ }^{22}$ these are not age-specific, an important issue given the distinctive etiologies of behavioral disturbance in the elderly compared with younger adult groups.

As much as posing a risk to themselves, despite their frailty, severely agitated elderly patients can pose a physical risk to others. As part of a strategy to prevent and manage violence in the workplace, many hospitals in Australia have access to a duress response team, ${ }^{23}$ whose remit includes older persons. However, there is limited literature addressing the management of severely agitated elderly patients by duress response teams with the exception of 1 study of agitated adult patients (mean aged 32 years) in an ED. ${ }^{24}$ A prospective study of parenteral sedation for agitated elderly patients (65 years and older) in an ED focused on the use of parenteral sedation only rather than the reasons for sedation and the use of alternative nonpharmacological strategies. ${ }^{25}$

The aim of this study was to describe the management of severely agitated elderly patients in an acute hospital setting, by analyzing a cohort of patients who required a response from the hospital's duress response team, known as the Aggression Response Team (ART). We aimed to describe the older patient population referred for ART calls, the reasons for and interventions during ART calls (including the use and nature of pharmacological sedation), complications arising from these interventions, and the follow-up of ART calls.

\section{Methods}

\section{Setting}

This study took place in a 300-bed suburban hospital in Sydney, Australia. Elderly patients are predominantly admitted under either general medical or surgical teams, with the availability of both geriatric and psychiatry consult-liaison services. There is no locked ward or deliriumdementia unit. The ART can be alerted via the pager system when there is a severely agitated patient and a staff member has concerns for the safety of either the patient or others. The team comprises a medical and psychiatry registrar (each with 2 or more years of post-graduate experience), a senior nurse acting as team leader, and security guards. The team leaders and security guards have mandatory annual face-to-face training in de-escalation strategies and restraint techniques. It is hospital policy that an "incident report" is recorded in the Incident Information Management System (IIMS) for all ART calls.

\section{Study design}

The study was a retrospective chart review. Patients 65 years and older who were referred for ART calls during 2014 in the ED or wards (excluding the psychiatry ward) were identified using the IIMS database ${ }^{26}$ and their medical records were reviewed.

Ethical approval for the study was obtained from the Northern Sydney Local Health District Human Research Ethics Committee. Patient consent was deemed not necessary by the Northern Sydney Local Health District Human Research Ethics Committee as the research was based on a de-identified file audit.

\section{Data collection and analysis}

Data was collected from the medical notes regarding demographics, medical history, regular medications, presenting symptom, and progress prior to the ART call. ART call details included time of activation (taken from the pager system), reasons for the ART call, working diagnosis documented in medical progress notes prior to the ART call, and interventions.

Details of pharmacological sedation were taken from the medication chart, including dose, route, and time of administration. Details regarding post-sedation monitoring were taken from the standard observation chart, or progress notes. Adverse events relating to observations were defined in alignment with the Standard Adult General Observation Chart calling criteria for clinical reviews, ${ }^{25}$ that is respiratory depression (respiratory rate $[\mathrm{RR}]<12$ ), hypotension (systolic blood pressure $[\mathrm{SBP}]<100$ ), and over-sedation (AVPU [alert, voice, pain, unresponsive] score $=\mathrm{P}$ or $\mathrm{U}$ ) (NSW Ministry of Health). ${ }^{27}$ Other adverse events identified from the notes included extrapyramidal side effects, missed or delayed usual medication, and falls over the 24 hours following sedation. Whether a patient had settled following 
sedation was based on documentation by either the nursing staff or medical team.

Simple statistical calculations such as mean, median, and standard deviation were performed using Microsoft Excel.

\section{Results}

\section{Patient demographics}

Of 73 ART calls identified from the IIMS database, there were 43 unique patients, including 26 with only 1 ART call, 12 with 2 calls, and 5 with 3 or more calls (maximum 6 ART calls, 1 patient). The mean age was 81 years (range 66-94 years, standard deviation 7.2 years), and 29 (67\%) patients were male. Other patient characteristics are presented in Table 1.

\section{Timing and location of ART calls}

Thirteen (18\%) ART calls occurred between 8 am and 4 pm, 35 (48\%) occurred between 4 pm and midnight, and 22 (30\%)

Table I Patient characteristics

\begin{tabular}{ll}
\hline Patient characteristics & $\begin{array}{l}\text { Number (percentage) } \\
\text { of patients }\end{array}$ \\
\hline Usual place of residence & \\
Independent living & $24(56 \%)$ \\
Low-level residential aged-care facility & $7(16 \%)$ \\
High-level residential aged-care facility & $12(28 \%)$ \\
Reason for admission & \\
Acute behavioral disturbance & $22(51 \%)$ \\
Infective symptoms & $4(9 \%)$ \\
Falls & $4(9 \%)$ \\
Cardiac symptoms & $4(9 \%)$ \\
Elective operation & $2(5 \%)$ \\
Constipation & $2(5 \%)$ \\
Other & $5(12 \%)$ \\
Past medical history & \\
Dementia & \\
Subtype unspecified & $13(30 \%)$ \\
Alzheimer's disease & $5(12 \%)$ \\
Dementia with Lewy bodies & $4(9 \%)$ \\
Frontotemporal dementia & $3(7 \%)$ \\
Vascular dementia & $3(7 \%)$ \\
Mixed Alzheimer's/vascular dementia & $1(2 \%)$ \\
Progressive supranuclear palsy & $1(2 \%)$ \\
Alcoholic dementia & $1(2 \%)$ \\
Total, all subtypes of dementia & $31(72 \%)$ \\
Psychiatric illness & \\
Depression & $8(19 \%)$ \\
Schizophrenia & $1(2 \%)$ \\
Schizoaffective disorder & $1(2 \%)$ \\
Substance abuse & \\
Alcohol dependence & $3(7 \%)$ \\
None of the above & $7(16 \%)$ \\
Psychotropic medications (preadmission) & $16(37 \%)$ \\
Antipsychotics & $13(30 \%)$ \\
Antidepressants & \\
Benzodiazepines & \\
Cholinesterase inhibitors & \\
Anti-epileptics & $(28 \%)$ \\
\hline
\end{tabular}

occurred between midnight and 8 am (ART call timing was unavailable for 3 cases). Five (7\%) of ART calls occurred in the ED, while 68 (93\%) occurred on the medical and surgical wards. The median time from triage to ART call was 1.9 days (range 21 minutes-16 days).

When looking at the pager system database (which did not include patient-specific identifiers), of the 326 ART calls regardless of age, there were 209 ART calls in the ED and 117 on the wards. IIMS reports were only filed for $50 \%$ of these ART calls; however, the rate was much better on the wards (71\%) compared to the ED (38\%). For those patients who did have IIMS reports, those on the wards $(83 \%)$ were 65 years or older, while in the ED only $10 \%$ were 65 years or older.

\section{Reasons for ART calls}

Reasons for ART calls were documented by both medical and nursing staff in 56 (77\%) of all the ART calls, by nursing staff alone in 15 ART calls and medical staff alone in 2 ART calls.

Multiple reasons for ART calls were given in 53 (73\%) cases, and a single reason was given in 20 (27\%). The most common reasons were wandering $(78 \%)$, physical aggression (66\%), and verbal aggression (47\%). Documentation limited the rating of severity of physical aggression, although examples included staff being physically struck, patients throwing files or equipment at staff, and 1 patient using a fire extinguisher as a weapon. For patients who had ART calls for wandering, often there was concern that the patient would abscond, and in some cases they had already left the building. Examples of documentation included, "Combative, resisting care. Verbally aggressive and threatening", "Climbing out of bed. Hitting and kicking staff", "Wanting to leave. Entered the lifts". Other reasons for ART calls included pulling out indwelling catheters or intravenous access.

In regards to diagnoses made by medical teams at the time of the ART call, 11 (26\%) had a working diagnosis of BPSD, 10 (23\%) had delirium, 9 (21\%) had BPSD and delirium, 2 (4\%) had primary psychosis, and 1 (2\%) had alcohol withdrawal, while 10 (23\%) did not have a documented working diagnosis.

\section{Interventions during ART calls}

There was documentation that verbal de-escalation had been attempted in the period, leading up to $31(42 \%)$ of the ART calls. In $14(19 \%)$ cases, the family was called in or spoke to the patient over the phone. In $16(22 \%)$ cases, a 1:1 special nurse was requested by the medical team, although it is unclear how often it was provided. Pharmacological sedation was used in $64(88 \%)$ of ART calls. Mechanical restraints were used in $10(14 \%)$ cases. 
Table 2 First pharmacological agents used in ART calls

\begin{tabular}{|c|c|c|c|c|}
\hline \multirow[t]{2}{*}{ Agent } & \multirow{2}{*}{$\begin{array}{l}\text { Number } \\
\text { (percentage) } \\
\text { of times used }\end{array}$} & \multicolumn{3}{|c|}{ Dose, mg } \\
\hline & & Mean & Min & Max \\
\hline Midazolam & 34 (53\%) & 2.7 & 1.0 & 5.0 \\
\hline Lorazepam & 7 (I I\%) & 0.7 & 0.5 & 1.0 \\
\hline Diazepam & $2(3 \%)$ & 13.0 & 6.0 & 20.0 \\
\hline Haloperidol & $10(16 \%)$ & 1.9 & 0.5 & 5.0 \\
\hline Risperidone & $5(8 \%)$ & 0.5 & 0.25 & 1.0 \\
\hline Olanzapine & $4(6 \%)$ & 5.0 & 5.0 & 5.0 \\
\hline Droperidol & I (2\%) & 10.0 & 10.0 & 10.0 \\
\hline Morphine & I (2\%) & 2.5 & 2.5 & 2.5 \\
\hline
\end{tabular}

Abbreviations: ART, Aggression Response Team; Min, minimum; Max, maximum.

In terms of pharmacological agents used, Table 2 presents the first agents used. Parenteral sedation was used in 48 $(75 \%)$ cases. The specific routes used were intramuscular in $32(50 \%)$ cases, intravenous in $12(19 \%)$ cases, subcutaneous in $4(6 \%)$ cases, and oral in $16(25 \%)$ cases. Of 48 cases where parenteral sedation was used, in only $16(33 \%)$ was it documented that oral sedation had been refused. The median time from the ART call to administration of the first agent was 13 minutes (range $0-45$ minutes). There were 5 cases in which dual agents were used simultaneously, and a further 9 cases in which the time from administration of the first agent to the second agent was less than 15 minutes. Overall, patients received further benzodiazepines or antipsychotics in $53(73 \%)$ of all ART calls with a mean time between first and second doses of 202 minutes (range 0-1,201 minutes).

\section{Post-sedation monitoring, complications, and follow-up of ART calls}

For those patients who received parenteral pharmacological sedation, the median time from sedation to their next set of observations was 120 minutes (range 5-1,530 minutes).

There were adverse events in $14 \%$ of ART calls. The sedation given in each of these cases is listed in Table 3.

Regarding follow-up of ART calls, there was review within 48 hours by psychiatry in $41 \%$ of cases, by geriatrics in $22 \%$, and by dementia Clinical Nurse Consultant in $36 \%$. There was review by at least one of the aforementioned departments in $62 \%$ of the cases. There was documentation that the family had been updated in $64 \%$ of the cases.

\section{Discussion}

To our knowledge, this is the first study to document the management of behavioral emergencies in the elderly in an acute hospital setting. Notwithstanding the significant limitations outlined in the Limitations section, our descriptive study provides an insight into the challenges of providing safe and effective management for the extremely agitated older persons in the acute hospital setting.

Not surprisingly, delirium and dementia were found to be the most common diagnoses in elderly referred to the ART. This is in contrast to studies of severe agitation in hospitalized younger adult patients, ${ }^{24}$ which have shown that functional psychiatric illness and substance abuse were the

Table 3 Psychotropic agent used in each case of adverse event

\begin{tabular}{|c|c|c|c|c|}
\hline Diagnoses & $\begin{array}{l}\text { First agent } \\
\text { (route, dose) }\end{array}$ & $\begin{array}{l}\text { Second agent } \\
\text { (route, dose) }\end{array}$ & $\begin{array}{l}\text { Time between } \\
\text { doses, minutes }\end{array}$ & Adverse effects \\
\hline Alzheimer's disease, BPSD & $\begin{array}{l}\text { Midazolam } \\
\text { (IV } 2.5 \mathrm{mg} \text { ) }\end{array}$ & $\begin{array}{l}\text { Midazolam } \\
\text { (IV I mg) }\end{array}$ & 5 & Hypotension, over-sedation \\
\hline $\begin{array}{l}\text { Frontotemporal dementia, } \\
\text { BPSD/delirium }\end{array}$ & $\begin{array}{l}\text { Olanzapine } \\
\text { (IM } 5 \mathrm{mg} \text { ) }\end{array}$ & $\mathrm{n} / \mathrm{a}$ & $\mathrm{n} / \mathrm{a}$ & $\begin{array}{l}\text { Over-sedation, hypoglycemia due to no } \\
\text { oral intake, missed regular medications }\end{array}$ \\
\hline $\begin{array}{l}\text { Alcohol-related dementia, } \\
\text { alcohol withdrawal }\end{array}$ & $\begin{array}{l}\text { Diazepam } \\
\text { (IV } 6 \text { mg) }\end{array}$ & $\begin{array}{l}\text { Diazepam } \\
\text { (IV } 2 \mathrm{mg} \text { ) }\end{array}$ & 8 & $\begin{array}{l}\text { Over-sedation, respiratory depression, } \\
\text { missed regular medications }\end{array}$ \\
\hline $\begin{array}{l}\text { Dementia (unspecified), } \\
\text { BPSD/delirium }\end{array}$ & $\begin{array}{l}\text { Midazolam } \\
\text { (IV } 5 \mathrm{mg} \text { ) }\end{array}$ & $\begin{array}{l}\text { Risperidone } \\
\text { (PO I mg) }\end{array}$ & Dual agents & Respiratory depression \\
\hline $\begin{array}{l}\text { Mixed Alzheimer's/vascular, } \\
\text { BPSD }\end{array}$ & $\begin{array}{l}\text { Midazolam } \\
\text { (IM I mg) }\end{array}$ & $\mathrm{n} / \mathrm{a}$ & $\mathrm{n} / \mathrm{a}$ & Missed regular medications \\
\hline $\begin{array}{l}\text { Dementia (unspecified), } \\
\text { melancholic depression }\end{array}$ & $\begin{array}{l}\text { Midazolam } \\
\text { (IM } 4 \mathrm{mg} \text { ) }\end{array}$ & $\begin{array}{l}\text { Lorazepam } \\
\text { (PO I mg) }\end{array}$ & 60 & Missed regular medications \\
\hline $\begin{array}{l}\text { Dementia (unspecified), } \\
\text { BPSD/delirium }\end{array}$ & $\begin{array}{l}\text { Midazolam } \\
\text { (IV } 2.5 \mathrm{mg} \text { ) }\end{array}$ & $\begin{array}{l}\text { Olanzapine } \\
\text { (IM } 5 \mathrm{mg} \text { ) }\end{array}$ & 30 & Respiratory depression \\
\hline $\begin{array}{l}\text { Schizoaffective disorder, } \\
\text { Parkinson's disease }\end{array}$ & $\begin{array}{l}\text { Haloperidol } \\
\text { (IM I mg) }\end{array}$ & $\begin{array}{l}\text { Lorazepam } \\
\text { (PO } 0.5 \mathrm{mg} \text { ) }\end{array}$ & 130 & Fall \\
\hline Delirium & $\begin{array}{l}\text { Haloperidol } \\
\text { (IV } 0.5 \mathrm{mg} \text { ) }\end{array}$ & $\mathrm{n} / \mathrm{a}$ & $\mathrm{n} / \mathrm{a}$ & Skin tear \\
\hline $\begin{array}{l}\text { Dementia with Lewy bodies, } \\
\text { Schizophrenia, BPSD }\end{array}$ & $\begin{array}{l}\text { Morphine } \\
\text { (SC } 2.5 \mathrm{mg} \text { ) }\end{array}$ & $\mathrm{n} / \mathrm{a}$ & $\mathrm{n} / \mathrm{a}$ & Missed regular medications \\
\hline
\end{tabular}

Abbreviations: n/a, not applicable; IV, intravenous; IM, intramuscular; BPSD, behavioral and psychological symptoms of dementia; SC, subcutaneous; PO, per oral. 
most common diagnoses, which only featured in $4 \%$ of our patients. Although not surprising, this finding has twofold significance. First, it reinforces the need for age-specific management guidelines for the behavioral emergency. Clearly, the management of agitation due to amphetamine-induced psychosis in a 22-year-old male must differ from agitation secondary to a urinary tract infection in an 82-year-old male. Second, this is a pointer for prevention. This finding reinforces what is already known in the literature on delirium, namely that we need to be attentive to high-risk groups for delirium and BPSD and target modifiable risk factors as part of a prevention strategy. ${ }^{10}$ If a patient comes in to ED with a history of BPSD, we must be alert for the potential for agitation. A study of older patients admitted to a tertiary care teaching hospital through ED showed that patients with dementia and/or delirium who become symptomatic after admission first show mental signs and symptoms, then show behavioral disturbances, which appear to be the proximate causes of greater length of stay. ${ }^{9}$

Interestingly, our clinical experience of the typical nursing home patient referred to hospital with BPSD was not reflected in this data, which although based on a small sample size showed that the majority of patients referred for ART calls were from home or low-level care, not high-level residential care. Are patients with cognitive impairment from home even more at risk of becoming frightened and agitated in the acute hospital? Are they underestimated in terms of their propensity for escalation compared with nursing home patients? Given the known risk of functional decline and institutionalization following severe or prolonged delirium or hospitalization per se, ${ }^{6-8}$ this provides further impetus for the need for prevention strategies.

Consistent with previous literature, ${ }^{28}$ and presumably reflective of both staffing levels and the inherent nature of behavior disturbance associated with delirium and dementia, referrals to the ART team frequently occur outside of normal working hours. This is another pointer to prevention and management. If recourse to the use of 1:1 nursing specials is an option, could this be geared to more vulnerable hours? Could there be negotiation with families to support patients during some of these hours, while recognizing the burden to families? Notably, as our study demonstrated, adverse effects from pharmacological sedation are not uncommon, and these are also potentially more dangerous in a less resourced afterhours setting.

Surprisingly, the majority of ART calls occurred on the wards rather than in the ED. However, it does not follow that there are fewer incidents of severe agitation in the ED compared to the wards, or that these patients are better managed in the ED given their lower reliance on ART calls. Rather, we believe this reflects less submission of IIMS reports due to time constraints, and also the different staffing in the ED, where there is less reliance on the ART (with its security guards) in order to manage these patients. Indeed, many patients received parenteral pharmacological sedation in the ED prior to having an ART call. There is clearly an equal obligation on EDs to be cognizant of the common reasons for agitation in elderly patients and to apply appropriate management strategies.

The reasons for ART calls were usually multifactorial; however, a common theme was a concern for the safety of the patient, staff, or others. There was a high prevalence of wandering among patients having ART calls, and we believe that this reflects the absence of both locked wards and a dedicated delirium unit at the study hospital. Notwithstanding the contextual basis for this, it must be emphasized that there is consensus in the literature that neither wandering nor verbal aggression (also commonly precipitating an ART call) is an indication for psychotropic use. ${ }^{29}$

As hypothesized, there was an extremely high reliance on pharmacological sedation. Based on the limited documentation, it is not clear that nonpharmacological interventions were exhausted in all cases. There were also some cases where the level of aggression did not appear to represent imminent harm to the patient or others, although this is difficult to conclude with any certainty without better documentation or the use of objective sedation and agitation scales.

We found a significant variance in the choice and dose of pharmacological sedation. Midazolam was commonly used, which is of concern given the lack of evidence for benzodiazepines in managing acute agitation in the elderly, their potential to worsen delirium, ${ }^{10}$ and the limited circumstances in which they are appropriate in the management of BPSD. ${ }^{30}$ Doses of haloperidol up to maximum $5 \mathrm{mg}$ are of significant concern given its propensity for extrapyramidal side effects, dose-related mortality, and significant risk in dementia with Lewy bodies. There was a high reliance on parenteral sedation, which may reflect patient noncompliance with oral sedation; however, this was not formally documented in the majority of cases.

The lack of regular post-sedation monitoring is of great concern, given the vulnerability of elderly patients to adverse effects. There may be several factors contributing to this, including: a lack of specific guidelines on the frequency of observations required post-sedation, a fear from nursing and medical staff that regular examination of the patient may 
further agitate the patient, and perhaps a lack of awareness of side effects of sedation. However, our study demonstrated a relatively high rate of adverse events following the use of pharmacological sedation, and hence should be a cautionary reminder of the need to monitor these patients carefully.

\section{Limitations}

There are a number of limitations to our study. First, and foremost, we recognize that these are site-specific findings, acknowledging the primary role of staffing and environment in the management of behavioral symptoms. ${ }^{5}$ It is a small cohort from a single center over a 1 year time period, the resources and staffing of which may have influenced the findings, limiting their generalizability. Specifically, the lack of a secured ward or specialized delirium unit is likely to have influenced the management strategies utilized.

Second, the data captured only those registered on the incident monitoring system, and therefore represented only a proportion of actual incidents of aggression. This may have led to the inclusion of more severely agitated patients. Notwithstanding this, we need to know how to manage inpatients on the very severe end of the behavior spectrum, within "Tier 7" of an Australian hierarchical model of BPSD service delivery. ${ }^{31}$

Third, as a retrospective chart-based study, the quality of the data was determined by the quality of naturalistic clinical documentation. This probably had impact on several variables such as diagnosis, such that subjects may have been misclassified as dementia or delirium, or, as commonly seen in acute settings, delirium may have been missed. ${ }^{10}$ Additionally, the "bare minimum approach" to documentation, particularly of behavioral or nonpharmacological strategies may have led to underestimation of the utilization of these.

\section{Conclusion and recommendations}

In this retrospective chart audit of patients referred to a duress response team, we observed a high frequency of recourse to pharmacological sedation of severely agitated elderly patients, with significant variance in the choice and dose of sedation and a high rate of complications arising from sedation. Albeit that our findings may be site specific, in the absence of any other such data in the literature, and indeed guidelines for such clinical scenarios, and in the face of management approaches of older patients being subsumed within general adult guidelines, this is a start. It is a start toward the development of some consensual guidelines for the management of the behavioral emergency in the older person, not for "emergency sedation of the elderly" which is not our goal, but our default option. We recommend the development of guidelines and education on the management of behavioral emergency in the elderly patients, including nonpharmacological de-escalation strategies tailored toward patients with dementia and/or delirium, and standardized psychotropic guidelines.

\section{Author contributions}

D Simpkins designed the study, collected the data, carried out the statistical analysis, and wrote the article. C Peisah and I Boyatzis assisted with designing the study, analyzing the data, and writing the article.

\section{Disclosure}

$\mathrm{C}$ Peisah is a former recipient of honorarium and travel and research support from Pfizer, Janssen, Cilag, Ely Lilly, Eisai, and Lundbeck. The abstract of this paper was presented at The Australian and New Zealand Society for Geriatric Medicine Annual Scientific Meeting 2016, "The AGEnder Paradox", 1-3 June 2016, Cairns Convention Centre, Cairns City, QLS, Australia, and the abstract has been published in Australasian Journal on Ageing Special Issue: The Australian and New Zealand Society for Geriatric Medicine Annual Scientific Meeting 2016, "The AGEnder Paradox", Volume 35, Issue Supplement S1, pages 18-41, June 2016. The authors report no other conflicts of interest in this work.

\section{References}

1. Nassisi D, Korc B, Hahn S, Bruns J, Jagoda A. The evaluation and management of the acutely agitated elderly patient. Mt Sinai J Med. 2006;73(7):976-984.

2. Peisah C, Chan DK, McKay R, Kurrle SE, Reutens SG. Practical guidelines for the acute emergency sedation of the severely agitated older patient. Intern Med J. 2011;41(9):651-657.

3. Piechniczek-Buczek J. Psychiatric emergencies in the elderly population. Emerg Med Clin North Am. 2006;24(2):467-490.

4. Valeriani L. Management of demented patients in the emergency department. Int J Alzheimers Dis. 2011;2011:840312.

5. Goldberg SE, Bradshaw LE, Kearney FC, et al. Care in specialist medical and mental health unit compared with standard care for older people with cognitive impairment admitted to general hospital: randomised controlled trial (NIHR TEAM trial). BMJ. 2013;347:f4132.

6. Draper B, Karmel R, Gibson D, Peut A, Anderson P. The Hospital Dementia Services Project: age differences in hospital stays for older people with and without dementia. Int Psychogeriatr. 2011;23(10): 1649-1658.

7. Fong TG, Jones RN, Marcantonio ER, et al. Adverse outcomes after hospitalization and delirium in persons with Alzheimer disease. Ann Intern Med. 2012;156(12):848-856.

8. Mukadam N, Sampson EL. A systematic review of the prevalence, associations and outcomes of dementia in older general hospital inpatients. Int Psychogeriatr. 2011;23(3):344-355.

9. Saravay SM, Kaplowitz M, Kurek J, et al. How do delirium and dementia increase length of stay of elderly general medical inpatients? Psychosomatics. 2004;45(3):235-242. 
10. Fong TG, Tulebaev SR, Inouye SK. Delirium in elderly adults: diagnosis, prevention and treatment. Nat Rev Neurol. 2009;5(4):210-220.

11. Lyketsos CG, Steinberg M, Tschanz JT, Norton MC, Steffens DC, Breitner JC. Mental and behavioral disturbances in dementia: findings from the cache county study on memory in aging. Am J Psychiatry. 2000;157(5):708-714.

12. O'Connor DW, Ames D, Gardner B, King M. Psychosocial treatments of behavior symptoms in dementia: a systematic review of reports meeting quality standards. Int Psychogeriatr. 2009;21(2):225-240.

13. Australian and New Zealand Society for Geriatric Medicine. Position Statement 13: Delirium in Older People. Revised 2012. Available from: http://www.anzsgm.org/documents/PS13Deliriumstatement Revision2012.pdf. Accessed November 5, 2015.

14. NSW Ministry of Health and the Royal Australian and New Zealand College of Psychiatrists. Assessment and Management of People with Behavioural and Psychological Symptoms of Dementia (BPSD). A Handbook for NSW Health Clinicians. Sydney, NSW: NSW Ministry of Health; 2013.

15. Tropea J, Gray L, Snell T. Policy and practice update: clinical practice guidelines for the management of delirium in older people in Australia. Australas J Ageing. 2006;27(3):150-156.

16. Vickland V, Chilko N, Draper B, Low LF, O'Connor D, Brodaty H. Individualized guidelines for the management of aggression in dementiaPart 1: key concepts. Int Psychogeriatr. 2012;24(7):1112-1124.

17. Ballard CG, Waite J, Birks J. Atypical antipsychotics for aggression and psychosis in Alzheimer's disease. Cochrane Database Syst Rev. 2006; CD003476.

18. Bourne R, Tahir TA, Borthwick M, Sampson EL. Drug treatment of delirium: past, present and future. J Psychosom Res. 2008;65(3):273-282.

19. Carson S, McDonagh MS, Peterson K. A systematic review of the efficacy and safety of atypical antipsychotics in patients with psychological and behavioural symptoms of dementia. J Am Geriatr Soc. 2006; 54(2):354-361.

20. Lonegran E, Britton AM, Luxenberg J, Wyller T. Antipsychotics for delirium. Cochrane Database Syst Rev. 2007;(2):CD005594.

21. Sink KM, Holden KF, Yaffe K. Pharmacological treatment of neuropsychiatric symptoms of dementia: a review of the evidence. JAMA. 2005;293(5):596-608.
22. Richmond JS, Berlin JS, Fishkind AB, et al. Verbal de-escalation of the agitated patient: consensus statement of the American association for emergency psychiatry project BETA de-escalation workgroup. West J Emerg Med. 2012;13(1):17-25.

23. NSW Ministry of Health. Preventing and Managing Violence in the NSW Health Workplace - A Zero Tolerance Approach. Sydney, NSW: NSW Ministry of Health; 2015.

24. Downes MA, Healy P, Page CB, Bryant JL, Isbister GK. Structured team approach to the agitated patient in the emergency department. Emerg Med Australas. 2009;21(3):196-202.

25. Calver L, Isbister GK. Parenteral sedation of elderly patients with acute behavioral disturbance in the ED. Am J Emerg Med. 2013;31(6): 970-973.

26. NSW Ministry of Health. Incident Management Policy. Sydney, NSW: NSW Ministry of Health; 2014.

27. NSW Ministry of Health. Standard Adult General Observation Chart (SAGO). Available from: http://www.cec.health.nsw.gov.au/_data/assets/ pdf_file/0012/258699/sago-12.2013.pdf. Accessed November 5, 2015.

28. Neumann RD, Faris P, Klassen R. Examining trends in the administration of "as needed" medications to inpatients with behavioral and psychological symptoms of dementia. Am J Alzheimers Dis Other Demen. 2015;30(3):247-256.

29. Peisah C, Skladzien E. The Use of Restraints and Psychotropic Medications in People with Dementia: A Report for Alzheimer's Australia Available from: https://www.fightdementia.org.au/files/NATIONAL/ documents/Alzheimers-Australia-Numbered-Publication-38.pdf. Accessed May 30, 2014.

30. Tampi RR, Tampi JD. Efficacy and tolerability of benzodiazepines for the treatment of behavioral and psychological symptoms of dementia: a systematic review of randomized controlled trials. Am J Alzheimers Dis. 2014;29(7):565-574.

31. Brodaty H, Draper BM, Low LF. Behavioural and psychological symptoms of dementia: a seven-tiered model of service delivery. Med J Aust. 2003;178(5):231-234.
Clinical Interventions in Aging

\section{Publish your work in this journal}

Clinical Interventions in Aging is an international, peer-reviewed journal focusing on evidence-based reports on the value or lack thereof of treatments intended to prevent or delay the onset of maladaptive correlates of aging in human beings. This journal is indexed on PubMed Central, MedLine,

\section{Dovepress}

CAS, Scopus and the Elsevier Bibliographic databases. The manuscript management system is completely online and includes a very quick and fair peer-review system, which is all easy to use. Visit http://www.dovepress. com/testimonials.php to read real quotes from published authors. 